\title{
Piezographie in the service of edentulous: clinical Case Report
}

\author{
AlaEddine Mahfoudhi', Oumaima Tayari', Amani Mizouri, ', Jamila Jaouadi ${ }^{1}$ \\ ${ }^{1}$ Department of removable complete Denture, Faculty of Dental Medicine of Monastir, Oral health and Oral-Facial \\ Rehabilitation Laboratory Research (LR12ES11), University of Monastir, Monastir, Tunisia \\ *Correspondent email: alaaeddinemahfoudhi@yahoo.com
}

Submit: 20/5/2021 | Accepted: 5/7/2021 | Published: 6/7/2021

\begin{abstract}
With senescence, edentulous patients present unfavorable clinical situations following the continued resorption of alveolar bone and the inevitable narrowing of the prosthetic corridor. That's why rehabilitation with removable complete prosthesis presents a difficult challenge for the dentist. In this connection, the use of the piezographic technique, a promising therapeutic approach, makes it possible to better respect the physiology of the elderly patient while ensuring a compromise of retention, prosthesis stability and comfort. The aim of this manuscript is to present the different stages of realizing a removable complete denture resulting from an impression of the bearing surfaces and a piezographic recording of the prosthetic corridor through a clinical case.
\end{abstract}

Keywords: Completely edentulous, mandibular resorption, piezographic, neutral zone, prosthetic corridor, impression. 


\section{Introduction}

The age of edentment often alter the anatomical and physiological structures, especially the bearing surfaces, and then followed by a retraction of the prosthetic corridor in relation with bone resorption. ${ }^{(1)}$

Nowadays, the dental implant therapy may be a treatment of choice for improving the denture stability and retention. ${ }^{(2)}$

Even in the era of implantology, and face to clinical situations in edentulous patients with advanced mandibular resorption (class III and class IV of Sangiuolo), piezographic technique (impression and registration) remains an excellent option to overcome prosthetic instability. ${ }^{(3)}$

Therefore, the use of the neutral zone by piezographic recording led to have a complete prosthesis respecting the physiology of the para prosthetic organs due to respecting the limits and better organization of the prosthetic teeth and the contour of the polished surface of the prosthesis. ${ }^{(4)}$ hypertrophy in the right maxillary tuberosity. (fig1).

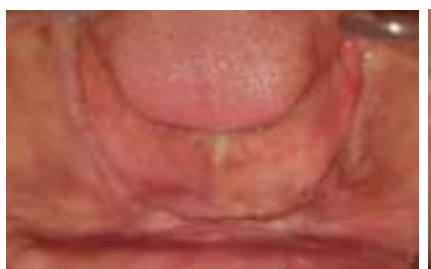

(A)

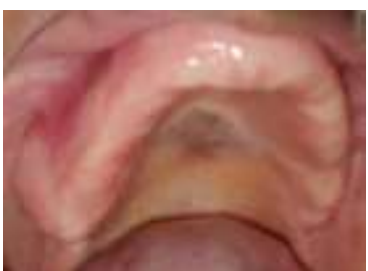

(B)
Figure1: Clinical appearance of oral morphology consultation
A: View of the mandible
B: View of maxillary

Panoramic radiography showed an increased bone resorption in mandibular anatomical landforms.

Bone resorption was marked with circles on the radiographies (fig2)

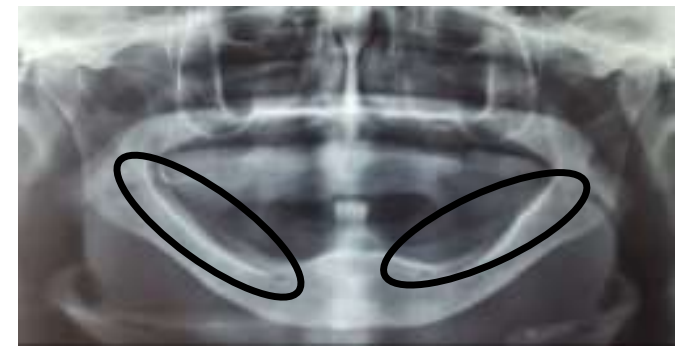

Figure 2: Panoramic radiography

Face to this advanced resorption, we adopted the piezographic technique to better record the prosthetic seat and delimit the prosthetic corridor, in which the mandibular prosthesis will be elaborated, by recording the muscular activity of the para-prosthetic organs by using the alternation between the pressure of the tongue and the buccinatolabial strap during phonation and swallowing. 


\section{Clinical steps}

Primary impression

After the select and rectification of the schreinmackers tray, the primary impression was make with Alginate. (fig3)

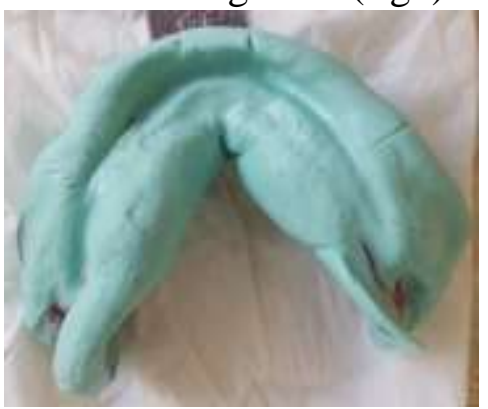

(A)
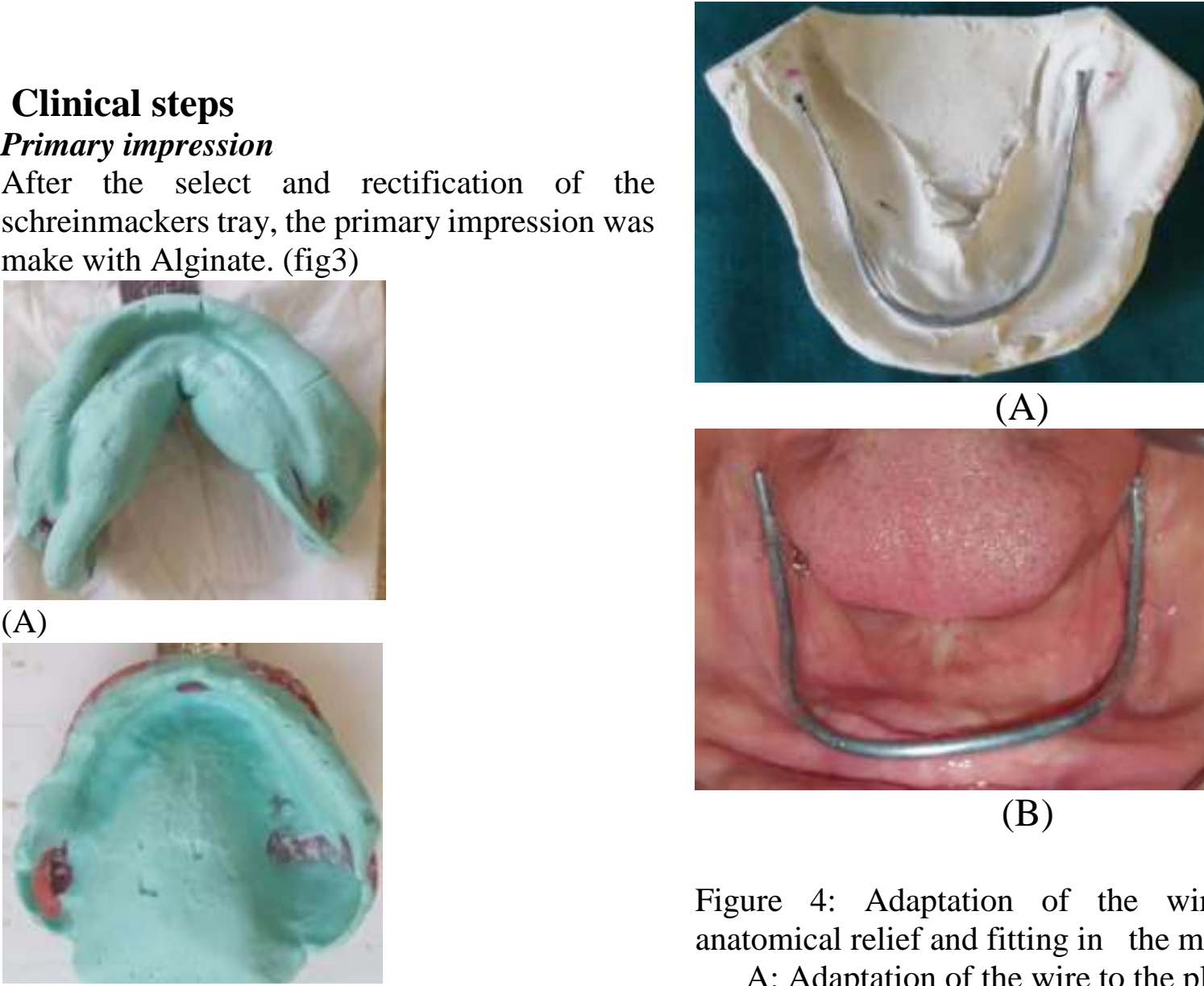

(A)

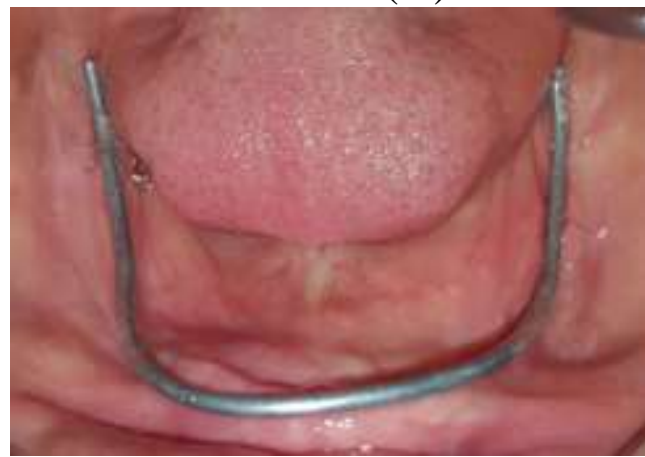

(B)

Figure 4: Adaptation of the wire to the anatomical relief and fitting in the mouth

A: Adaptation of the wire to the plaster cast

B: try-in of the wire in the mouth

Figure 3: Primary impression with Alginate

A: Primary Mandible impression

B: Primary maxillary impression

On the mandibular cast, a lead wire was preformed according to the configuration of the arch while respecting the peak of the ridge and then tried in the mouth. The stability of this wire should be found at rest and during function. The wire will serve as a material support during taking the primary piezographic impression. (fig4).

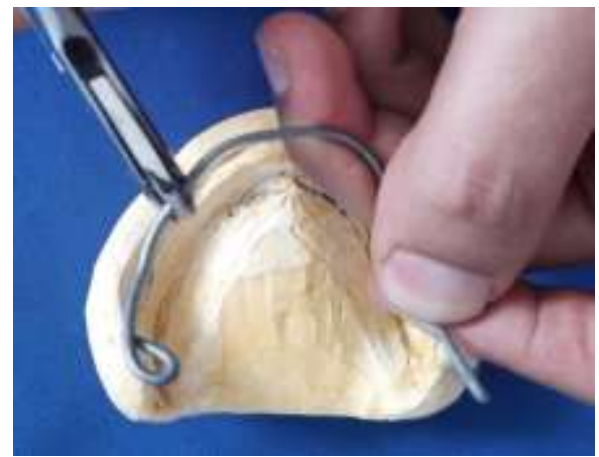

Figure 5: rectification of the wire with the paperclip (clamp) 
The technic procedure was explained to the patient beforehand.

Then to avoid with a successive addition of the material (polysulfide) that it stuck to fingers we used to put the material in container with cold water. The wire was introduced into the mouth and the patient was invited to pronounce some phonemes by repeating a typical sequence (SIS, SO, TE, DE, SE, ME, PE) until the paste is no longer modifiable.

The polysulfide has been placed in container with cold water to promote a certain viscosity to provide the modeling and to shape the material by the oral functions.

This manouvre was repeated several times until a global record of the mandibular ridge was obtained. (fig6)

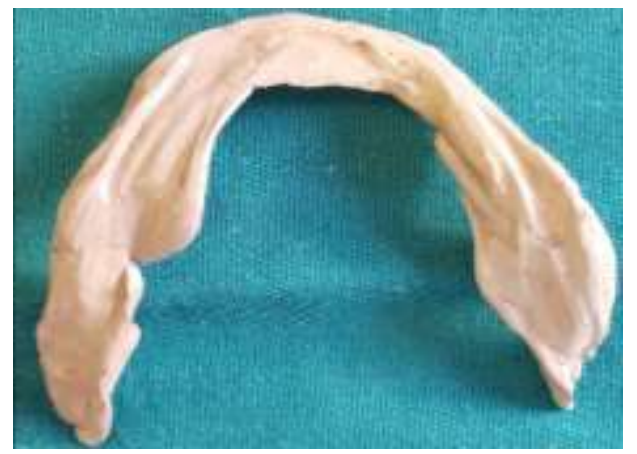

Figure 6: Over all Mandibular Crest Horizontal Plane impression

Successive additions the perform eminences, the retro molar regions by modelling with fingers until the material set Also, at the sublingual area, the incision masseterin and the oral and mylohyoidian regions until having a complete record. While phonation, the wire must be perfectly stable: the visual inspection must be confirmed since this technique requires the cooperation of the patient. If this check is negative, it is necessary to remove the last addition and repeat this step.

The forces exerted by muscles will tend to stabilize the wire during the functions. Subsequently, a surfacing of the entire impression with low viscosity silicone ensures a delicate recording of all anatomic elements, to have a smooth and clear surfaces, which make it possible to finish the piezographic primary impression. (fig7)

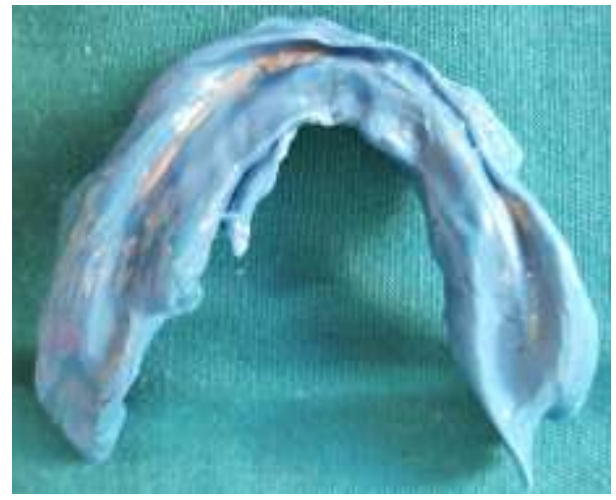

Figure 7: Primary piezographic impression

A comparison between the cast derived from the conventional primary impression and the one derived from the piezographic primary impression shows the difference in the quality of the anatomic landforms recorded. (The accuracy of the depth of the bottoms) (fig.8)

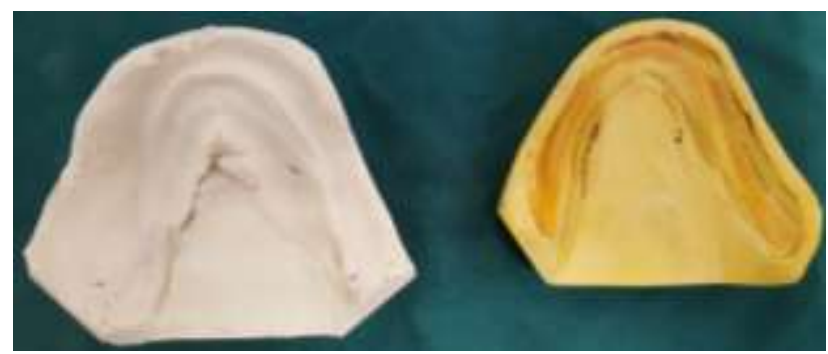

Figure 8: Comparison of casts from the conventional and piezographic primary impression

\section{Secondary impression:}

On the maxillary cast from the conventional primary impression, an individual impression tray (IIT) was made with self-curing resin. The individual mandibular impression tray was made on the cast derived from the primary piezographic impression. A discharge to the chin nerve, as it was noted the proximity of the chin foramen to the crestal edge, especially on the right side, was performed on the (IIT) before the impression was taken to minimize the pressure of this region and relieve the patient. 
The peripheral joint was conventional made at the maxillary level while at the mandibular level, the joint was made with Kerr paste only at the level of the perform eminences and the sublingual region which allows to gain retention and not interfere with the para prosthetic organs. (Using the technic of Bucchman). On the previous level, a joint with Kerr paste was made to restore a deficiency during the primary piezographic impression. A maxillary impression is taken under digital pressure with polysulfide whereas at the mandibular level, the impression was taken under occlusal pressure. (fig9).

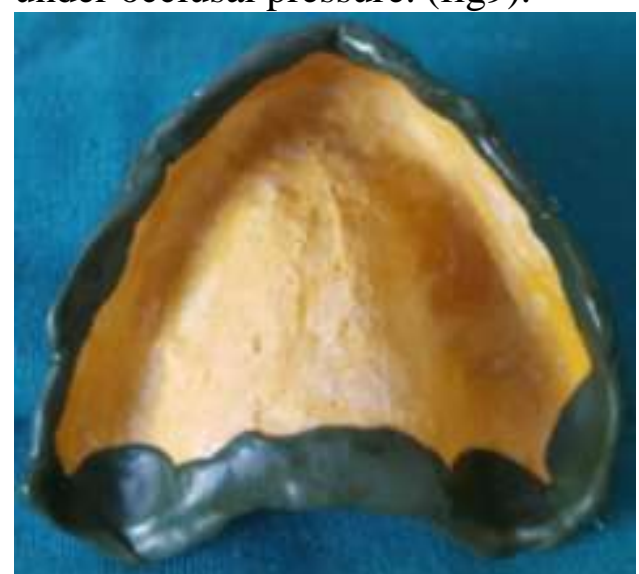

(A)

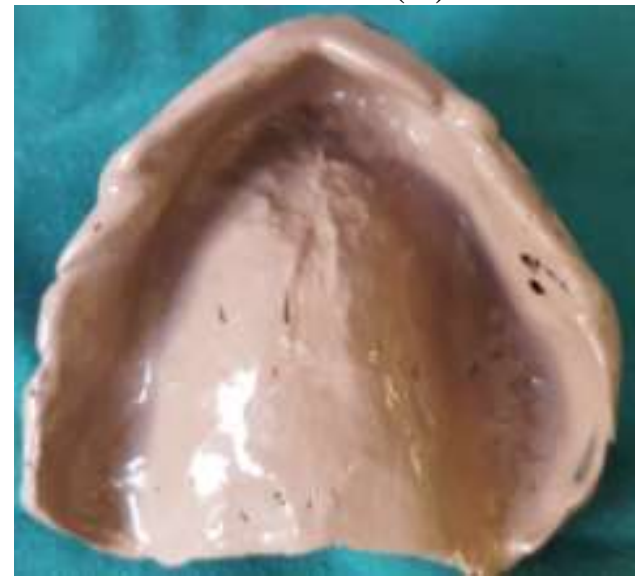

(B)

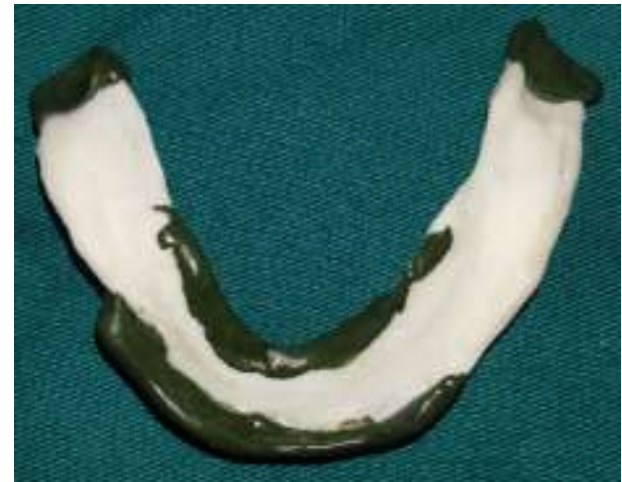

(C)

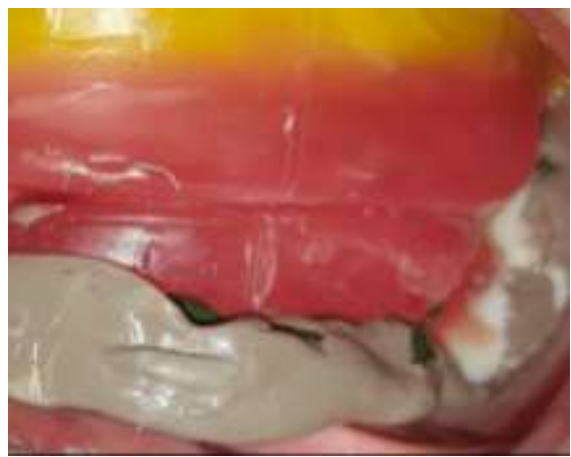

(D)

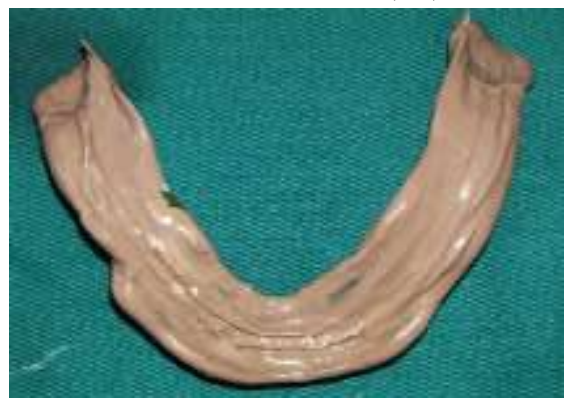

(E)

Figure 9: Maxillary and mandibular secondary impressions

a: Border molding with the thermoplastic paste zone by zone on the maxilla

b: Maxillary secondary impression

c: Border molding with the thermoplastic paste zone by zone mandibular

d: Mandibular secondary impression under occlusal pressure

e: Mandibular secondary impression

\section{Record Intermaxillary relation:}

A classic occlusion recording was performed. (fig 10) 


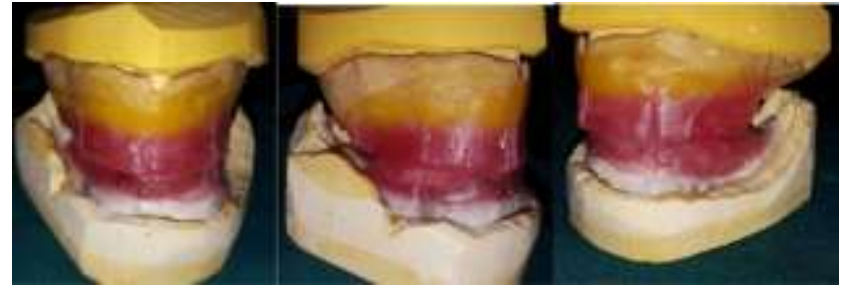

Figure 10: Record Intermaxillary Reports

\section{Piezographic recording of the prosthetic corridor}

Piezographic recording was made on a rigid base of well-adjusted auto resin from the secondary cast. This base must be stable in order to not interfere with the mobility of the para prosthetic organs. (fig11)

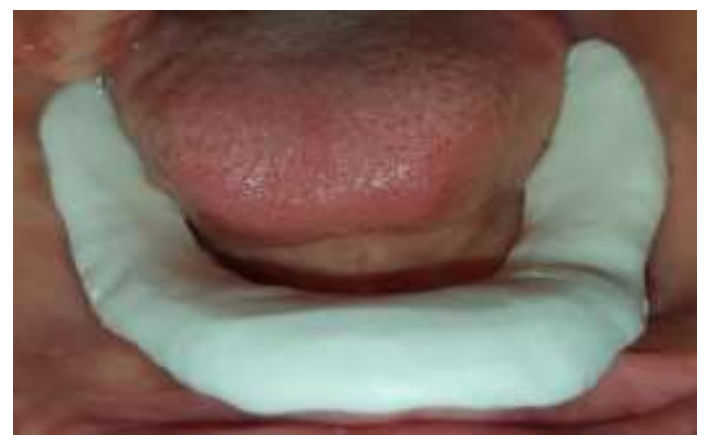

Figure 11: occlusion base

It is surmounted by a $1 \mathrm{~cm}$ thick wax pad that should not interfere with the tongue or the labial buccinato strap and does not disturb the patient to speak. This bead serves as a retention and consolidation element of the piezographic material. (fig12)

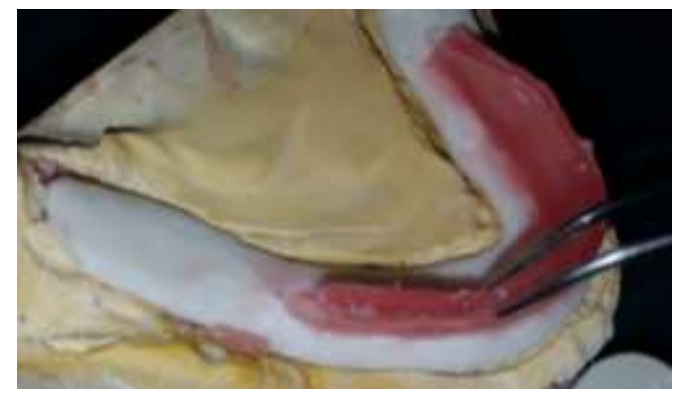

(A)

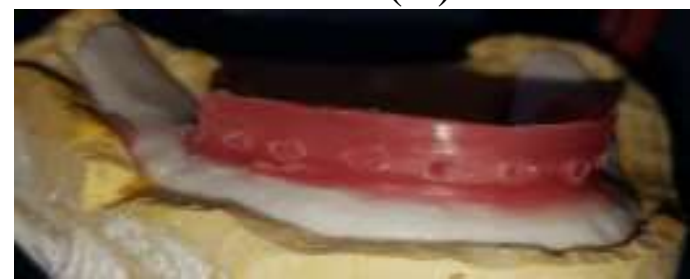

(B)

Figure 12: Occlusion base with material retention ring

A: Checking the thickness of the bead

B: Wax Perforations for Modelling Material Retention

After the preparation of the modeling material (high viscosity silicone in this case). It was deposited in the vestibular and lingual on the extrados of the base and having as support the wax band. (fig13)

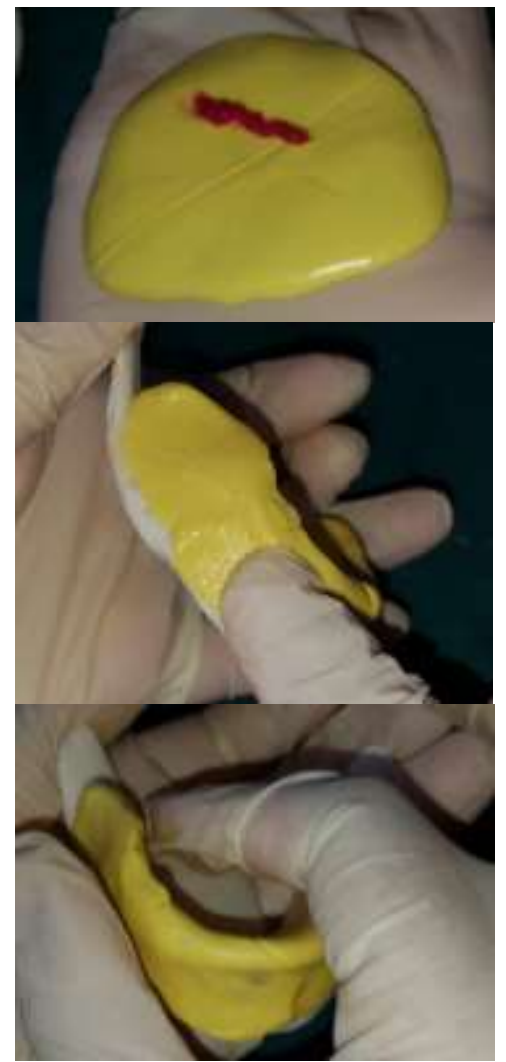

Figure 13: Shaping material

After introduction of the base in the mouth, the patient was asked to repeat after the operator 6 times "SIS" and once "SO" in order to record the oral region, also "SE", "TE" and "DE" for recording the anterior region by the centrifugal action of the tongue. These phonemes are renewed until the material is rigid enough to no longer be deformed by the oral organs. These movements are alternated by those of swallowing. (fig 14) 


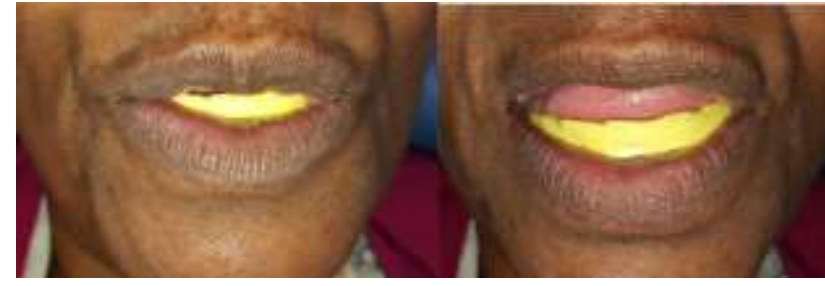

Figure 14: Basic piezographic record in mouth

When the material is removed, the most prone part was marked at this piezogram and the piezographic occlusion plane was obtained. The prone part of each record: posterior and anterior). (fig15)
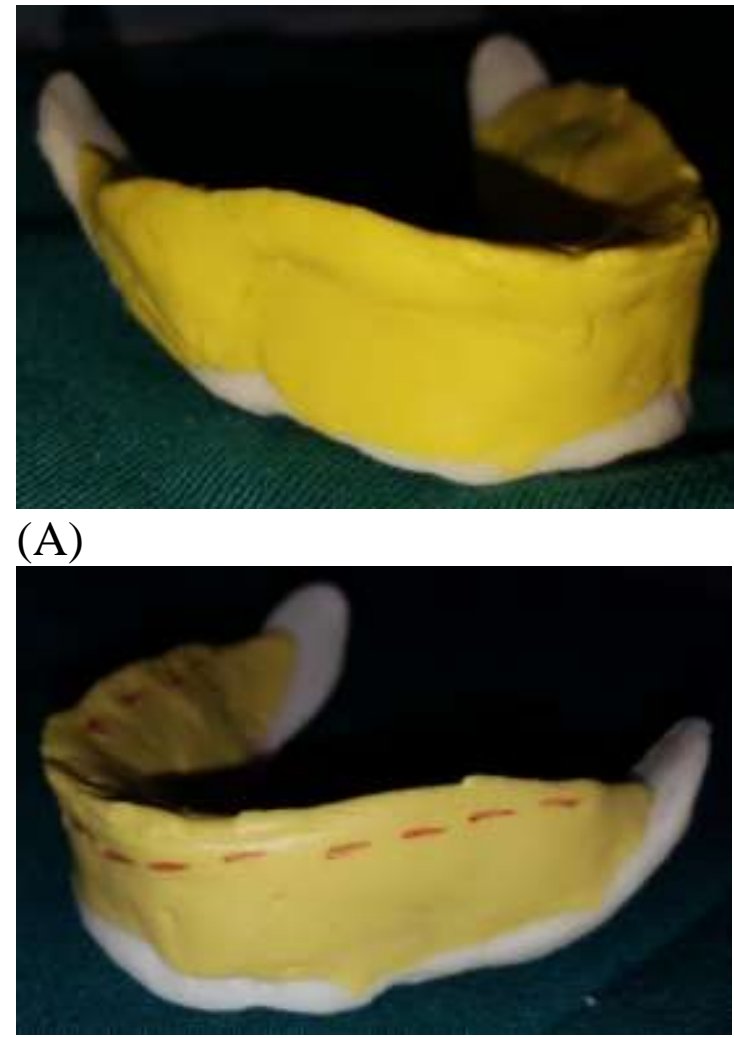

(B)

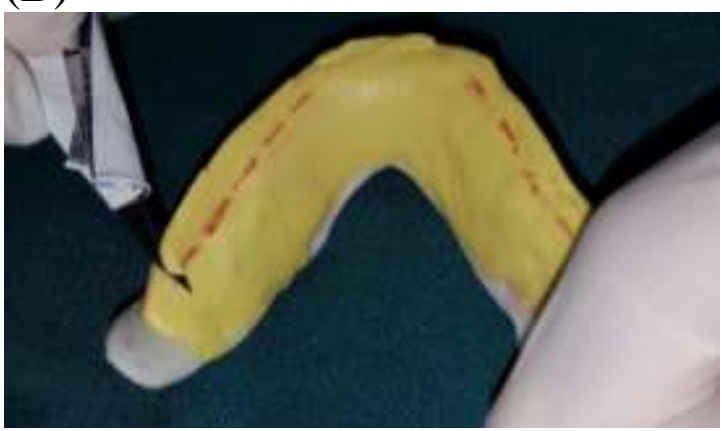

(C)

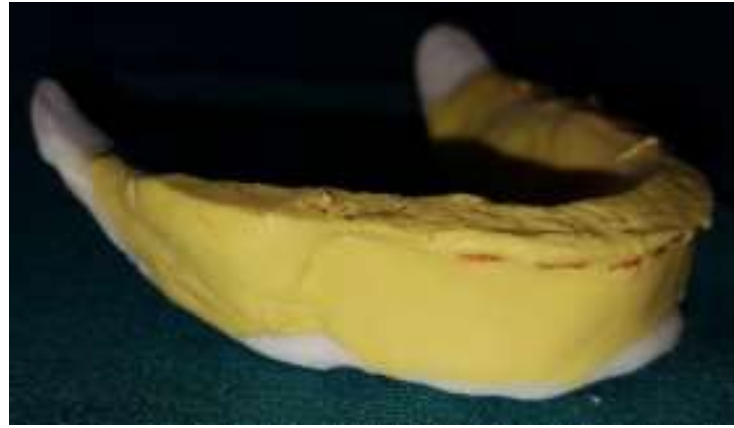

(D)

Figure 15: Determination of the piezographic occlusion plane.

A: The base with the piezogram

B: Marking of the piezographic plane occlusion

C: Elimination of excess

D: Piezographic occlusion plane determination

The next step was to complete the prosthetic plan, which is a compromise between the conventional occlusion plan and the piezographic occlusion plan. This plan was determinated after laying the base with its piezogram on the secondary model already mounted on articulator. At the closure, the incisal pin does not touch the table, it is for this reason that modification were done at the level of the maxillary and mandibular bans by homothetic subtraction until it reached the vertical dimension of occlusion marked by the touched of the incisal pin of the articulator. These corrections have always been guided by anatomical landmarks to locate the occlusion plane which are the $2 / 3$ of the perform eminence and the mid-distance of the vestibule bottoms. (fig16)

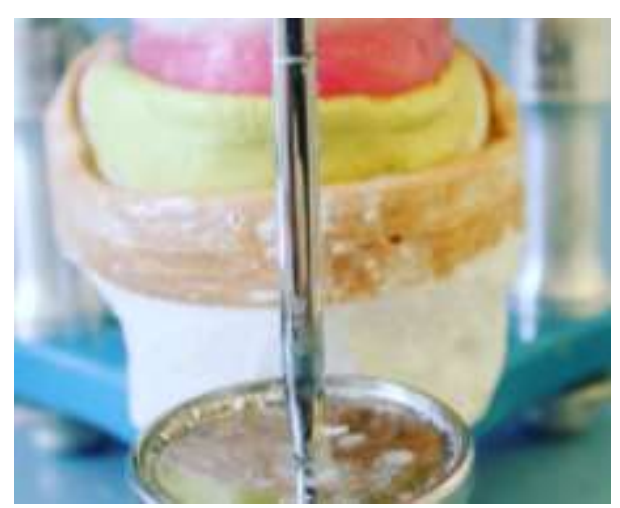

(A) 

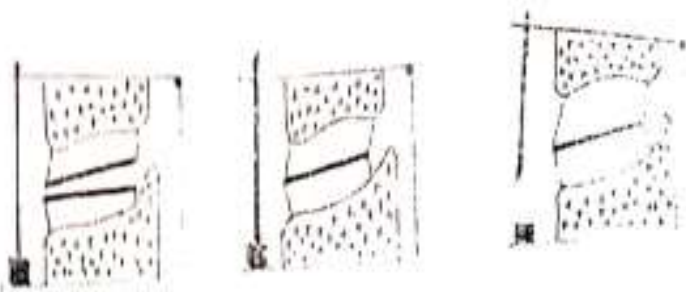

(B)

Figure 16: Comparison of the conventional occlusion plane with the piezographic plane

A: Perfect cooptation of the two ribs and the incisive stem in contact with the incisive plate

B: Schematic representation of different clinical situations

\section{Mounting of teeth}

A preliminary realization of the grooves on the cast facilitates the precise repositioning of the keys on the cast. The piezogram was formed with high viscosity silicone to give two vestibular and lingual keys to delimit the neutral zone already recorded.

The keys were made at the same height as the occlusion plane (fig17)

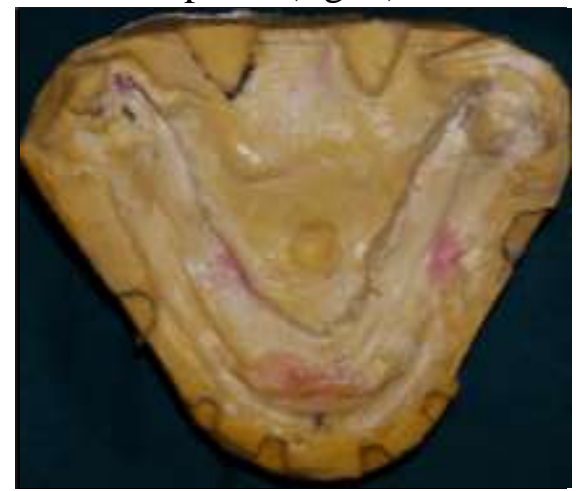

(A)

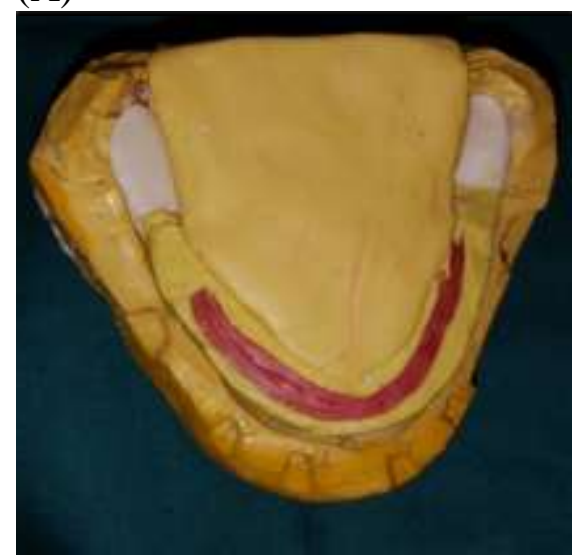

(B)

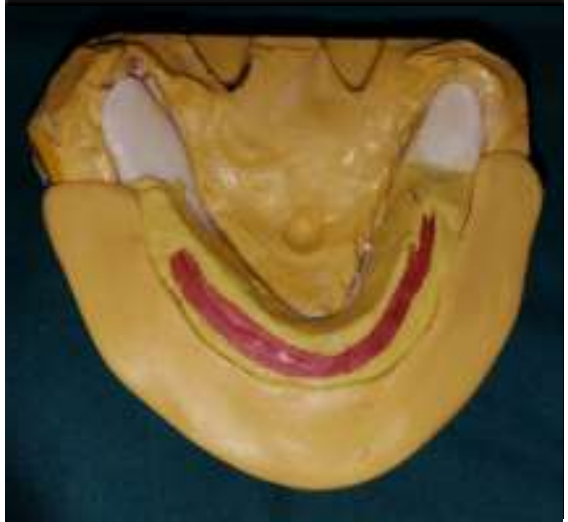

(C)

Figure 17: Piezogram formwork with silicone keys.

A: Retention grooves in the mandibular cast

B: Repositioning the Lingual Key $\mathrm{C}$ : Repositioning the vestibular key

The space delimited by the keys (prosthetic space) was poured in wax to give a cast materializing the prosthetic corridor designed for mounting mandibular prosthetic teeth. The mounting of the teeth must respect the morphology of this piezographic model. The assembly was made according to the concept of bilaterally balanced occlusion and always guided by the silicone keys in the vestiulolingual and occlusal direction. (fig18)

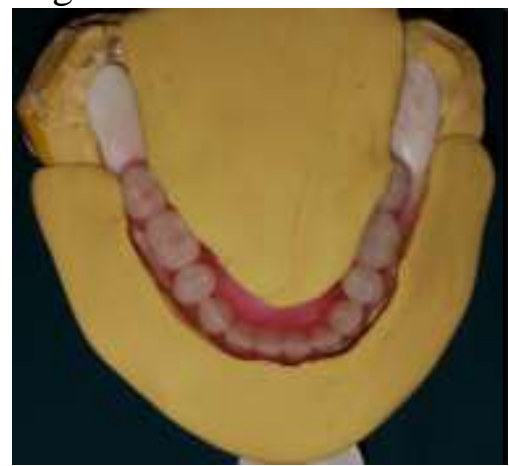

(A) 

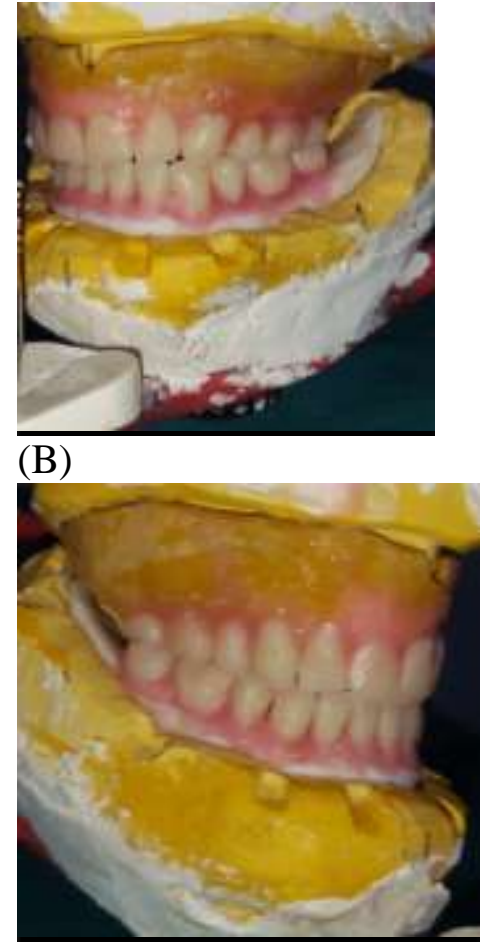

(C)

Figure 18: Mounting of teeth and control with silicone keys

A: Control of assembly with vestibular and lingual keys

B: Fitting the joint mounting

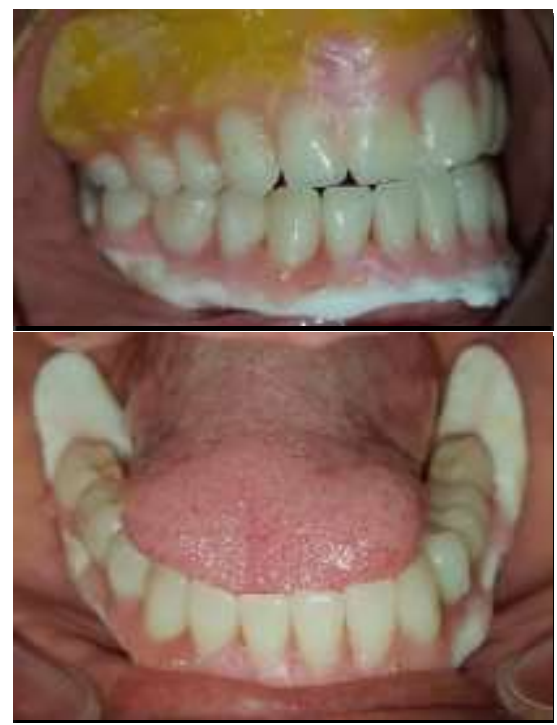

Figure 19: Fitting the teeth in the mouth

Once the assembly is validated in the mouth, we moved to the muffling and polymerization. (fig20).

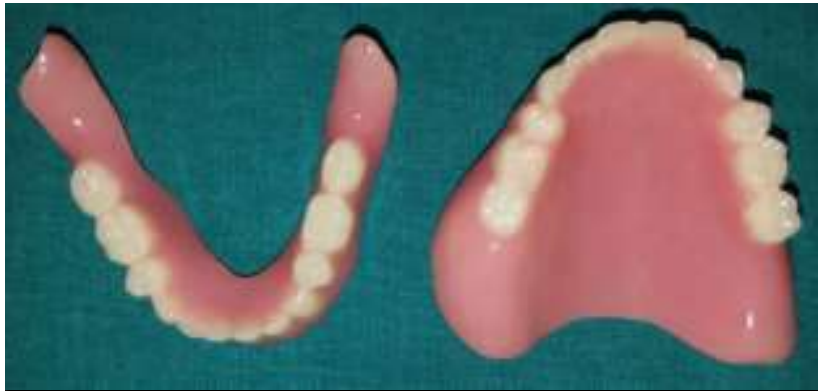

Figure 20: Finished and polished prosthesis

Follow ups the insertion (fig 21) of the prosthesis was supposed to be done more frequently to assess the prosthetic stability and patient's satisfaction but unfortunately due to the Corona shutdown this was not possible but communication with the patient was by phone.

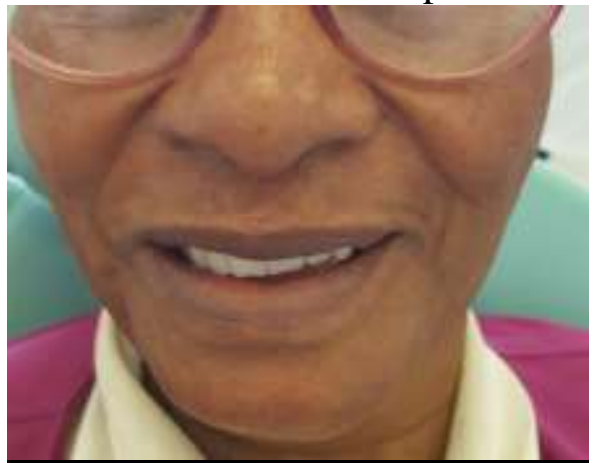

Figure 21: Insertion of the prosthesis

\section{Discussion}

Unstable lower complete denture problem since all oral functions, such as speech, mastication, swallowing, smiling, and laughing, involve the synergistic actions of the tongue, lips, cheeks, and floor of the mouth which are very complex and highly individual ${ }^{(1)}$.

Piezography is a therapeutic approach in which a plastic material is molded, (5) based on the muscular pressures that determine the available 
prosthetic space during the function and at rest. (6)

The functions requested during modeling are more often phonation, introduced by «KLEIN» ${ }^{(7)}$ since it is the most developed oral function and the least affected by the loss of teeth, and swallowing, introduced by «HEATH» which concluded that the lingual forces are greater than the vestibular ones.

But, we usually finds a vestibulated aspect of the prosthetic corridor recorded by the swallowing piezography compared to that which uses phonation. Similarly with phonetic techniques, the recorded neutral zone seems narrower at the posterior level thus limiting the positioning of the premolars and molars.

It is for this reason that we opted for the mixed technique of Professor Majdoub using both phonation and swallowing. For the materials used in the production of the piezographic impression, the ideal material should require the prerequisite criteria of stability and fidelity. ${ }^{(10)}$

It must have a sufficiently slow plasticity time to allow the various manipulations. ${ }^{(11)}$

It must also be biocompatible with no deformation.

For the secondary impression, the fact of making the peripheral joint only on the perform eminences and the sublingual zone will offer maximum stability and retention. ${ }^{(13)}$

According to PETER CLARKA the retro molar area undergoes less resorption over time and the extension at this level provides a stability that opposes the lateral displacement of the mandibular prosthesis.

Piezographic techniques allow to reduce unnecessary extensions and provide a correct contour after the proper registration of muscle attachments and movement of mucous membranes.

The prosthesis from a piezographic cast offer the patient greater freedom in his own daily functional possibilities.

(9)

The operation of the neutral zone promotes an improvement of the patient's ability to adapt to his prosthesis ${ }^{(13)}$, an improved phonation and better facial aesthetics compared to dentures whose teeth have been mounted on the crest because there is proper support by the surrounding muscles. ${ }^{(15,16)}$

Although some studies (16) reported that their participants subjectively felt that neutral zone dentures were more stable, retentive, and comfortable with minimum problems after insertion and better esthetics than conventionally fabricated dentures ${ }^{(17)}$, none of these studies used a measurable evaluation or a specifically designed questionnaire ${ }^{(3)}$

Mubashir and al ${ }^{(14)}$, concluded from their study that the level of satisfaction of patients with prosthesis performed according to piezographie technic is better than with conventional technic The results of the clinical study by Fahmy and Khayat revealed better comfort and clarity of phonation with prostheses placed in neutral space compared to conventional techniques ${ }^{(19)}$.

Diabetic patients are characterized by an accentuated resorption and even with the piezographic prosthesis appointment for controls and rebasing are necessary. Rebasing is considerate as a conservative clinical approach (instead of using implants) for the treatment of severely advanced resorbed ridges associated with unstable non retentive discomfort able bases (20)

\section{Conclusion}

Piezography contributes to therapeutic success and leads to a functional and psychological management of a patient who is physically impaired. Its principle is based on the exploitation of oral muscle behaviors in edentulous patients with the aim of optimizing the balance of the prostheses.

It must be well understood so that the process becomes a controlled necessity in patients who have increased mandibular resorption. But this approach still difficult to achieve by the practitioner especially since it requires a fairly long time and active cooperation of the often elderly patient. 


\section{References}

1. C. Peter, «Managing the Unstable Mandibular Complete Denture - Tooth Placement and the Polished Surface Dent Update,» vol. 7, n \%143, pp. 660-2, 6644, 669-70, 2016.

2. H. Rokhassi, Abdelkaoui A et N. Merzouk , «The piezographic impression technique in daily practice».

3. L. Berrenas et P. Odman, «Myodynamique and conventional construction of complete dentures: a comparative study of comfort and function.,»J Oral Rehabil, ${ }^{\circ} \% 116$, pp. 457-65, 1989.

4. R. Wafa'a, A. Swelem et A. Abdelnabi , «Effect on patient satisfaction of mandibular denture tooth arrangement in the neutral zone.,» The Journal of prosthetic dentistry, vol. $3, \mathrm{n}^{\circ} \% 1121$, pp. 440-446, 2019.

5. Le joyeux L, Mise en condition en prothèse adjointe, 1993.

6. A. Regragui, «Espace biofonctionnel et mise en condition tissulaire : quelles perspectives en prothèse amovible complète ?,» Actualités OdontoStomatologiques -, $\mathrm{n}^{\circ} \% 1225,2011$.

7. D. Bhorgonde et K. Nandakumar , «An evaluation of the position of the neutral zone in relation to the crest of mandibular alveolar ridge-An In-vivo study.,» Journal of international oral health, vol. $2, \mathrm{n}^{\circ} \% 16$, pp. 45-54, 2014.
8. Klein, «La piézographie : modelage dynamique ou volume prothétique,» Actual. Odonto-Stomatol, $\mathrm{n}^{\circ} \% 1106$, pp. 226-77, 1974.

9. A. Porwal, MDSa et S. Keiichi, $\ll P h D$ Current status of the neutral zone: A literature review,» J Prosthet Dent, vol. 2, n \% 1109, pp. 129-34, 2013.

10. L. Fajri , E. M. Bouabid et E. W. Wadaa, «La prothèse complète mandibulaire : stabilité et rétention,» Actualités odontostomatologiques, 2009.

11. A. Mustafa, «Effect of the lingual ledge of neutral zone impression on the retention and stability of mandibular complete denture in elders with atrophied alveolar ridge,» Tanta Dental Journal, vol. 12, n \% 12, pp. 111-118, 2015.

12. A. Regragui , A. Safrioui et A. Benfdil, «Couloir prothétique et gérodontologie : traitement simple pour une stabilité optimum,» Actualités OdontoStomatologiques, $\mathrm{n}^{\circ} \% 1258,2012$.

13. A. Sampierto, «Thèse de doctorat: Université de Nants,» 2013

14. M. Sharif, A. Azadd et S. Ahmad, «Comparison of patient's satisfaction level with complete dentures fabricated by neutral zone technique and conventional technique.,» Pakistan Oral Dental J 2013 ; 33(1):187-91, vol. 1, n \%133, pp. 187-91, 2013.

15. v. Beresin et F. Schiesser, «The neutral zone in complete dentures,» J Prosthet Dent., vol. 4, n \%136, pp. 356-67, 1976.

16. S. Chandra, «Management of a severely resorbed mandibular ridge with the neutral zone technique,» Contemp Clin Dent., vol. $1, \mathrm{n}^{\circ} \% 11$, pp. 36-39, 2010.

17. R. David, «The neutral zone revisited: from historical concepts to modern application,» J Prosthet Dent., vol. 6, $\mathrm{n}^{\circ} \% 1101, \mathrm{pp} .405-$ 12, 2009.

18. Y. Tayachi, J. Jaoudi et R. Bendhief, «Dealing with Mandibular Resorbed Ridge by Using the Neutral Zone Technique: About A Case Report,» Saudi J Oral Dent Res, vol. 2, n \% 15, pp. 111-119, 2020. 
19. M. Fahmy et D. Khayat, «A study of the importance of the neutral zone in complete dentures.,» J Prosthet Dent, ${ }^{\circ} \% 164$, pp. 456-62, 1990.

20. S. Jemli, A. Mahfoudhi et J. Jaouadi, «Rebasing as a Problem-Solving in Complete Dentures,» Saudi J Oral Dent Res, vol. 6, n \%16, pp. 227-233, 2021. 